\section{Membranes for Hydrogen Purification: An Important Step toward a Hydrogen- Based Economy}

\section{Tina M. Nenoff and Richard J. Spontak, Guest Editors, and Christopher M. Aberg}

\begin{abstract}
Production of pure molecular hydrogen is essential to the realization of the proposed "hydrogen economy" that could ultimately provide hydrogen as a clean, renewable source of energy; eliminate the industrialized world's dependence on petroleum; and reduce the generation of greenhouse gases linked to global warming. A crucial step in obtaining pure hydrogen is separating it from other gaseous compounds - mainly $\mathrm{CO}_{2}-$ that often accompany hydrogen in industrial chemical reactions. Advanced membrane technology may prove to be the key to the successful, economical production of molecular hydrogen.

Size-sieving glassy polymer membranes can separate $\mathrm{H}_{2}$ on the basis of its small size. Alternatively, reverse-selective rubbery polymers can expedite the passage and, hence, removal of $\mathrm{CO}_{2}$ due to its relatively high solubility in such membranes alone or in conjunction with dissociative chemical reactions. Transition-metal membranes and their alloys can adsorb $\mathrm{H}_{2}$ molecules, dissociate the molecules into $\mathrm{H}$ atoms for transport through interstitial sites, and subsequently recombine the $\mathrm{H}$ atoms to form molecular $\mathrm{H}_{2}$ again on the opposite membrane side. Microporous amorphous silica and zeolite membranes comprising thin films on a multilayer porous support exhibit good sorption selectivity and high diffusion mobilities for $\mathrm{H}_{2}$, leading to high $\mathrm{H}_{2}$ fluxes. Finally, carbon-based membranes, including carbon nanotubes, may be viable for $\mathrm{H}_{2}$ separation on the basis of selective surface flow and molecular sieving. A wide variety of materials challenges exist in hydrogen purification, and the objective of this issue of MRS Bulletin is to address those challenges and their potential solutions from basic principles.
\end{abstract}

Keywords: adsorption, carbon, diffusion, energy, film, hydrogen, membrane, metal, polymer, silica, zeolite.

\section{Introduction}

Although hydrogen composes $80 \%$ of all known matter in the universe-excluding the elusive "dark matter" whose nature is currently not known-it is not available in its free molecular form on
Earth. Here, it is tied up in the water that covers two-thirds of the planet, in the valuable hydrocarbon deposits that lie under the Earth's surface, and in countless other compounds. To obtain molecular hydrogen as a source of fuel requires the development of methods capable of separating hydrogen from carbon, oxygen, nitrogen, and other elements to which it is chemically bound. In some cases, such as in steam reforming of natural gas, described by the reaction

$$
\mathrm{CH}_{4}+2 \mathrm{H}_{2} \mathrm{O} \rightleftarrows \mathrm{CO}_{2}+4 \mathrm{H}_{2} \text {, }
$$

the separation of hydrogen from carbon and oxygen is accomplished on an industrial scale. However, molecular hydrogen is accompanied by $\mathrm{CO}_{2}$ as a reaction product, which requires another separation step to produce a stream of pure hydrogen.

The challenges of producing hydrogen on an industrial scale are tremendous, but so are the potential rewards: a source of clean, renewable fuel, which produces only water when burned; decreased production of polluting greenhouse gases; and abundant energy for most of the industrialized world, ending our reliance on petroleum resources that are diminishing and becoming increasingly expensive. While much attention has been recently and rightfully paid to $\mathrm{H}_{2}$ storage and fuel cell development, $\mathrm{H}_{2}$ separation and purification remain important considerations to achieving a "hydrogen economy." Furthermore, significant materials advances in membrane technology for $\mathrm{H}_{2}$ gas separation are needed to drive reductions in existing $\mathrm{H}_{2}$ production costs. The purpose of this issue of MRS Bulletin is to address the materials challenges that exist in hydrogen purification and present examples of the different types of membranes currently being explored for efficient and robust $\mathrm{H}_{2}$ production.

\section{The Drive Toward a Hydrogen Economy}

In January 2003, a U.S. presidential directive announced the $\$ 1.2$ billion Hydrogen Fuel Initiative, which has since generated tremendous interest in a "hydrogen economy" within the United States and catalyzed international cooperation efforts to bring such a global future to fruition. As it is envisioned, this hydrogen economy is one in which molecular $\mathrm{H}_{2}$ is produced from coal, natural gas, nuclear energy, or renewable sources such as biomass, wind, and solar energy. Following production, $\mathrm{H}_{2}$ would be distributed and stored, with its eventual use in fuel cells to generate energy, mostly for powering automobiles but also potentially for providing electricity and heat to residential, commercial, and industrial facilities. According to the U.S. Department of Energy (DOE), this overarching objective can be divided into four major research thrusts: production, 
distribution/transportation, storage, and fuel cell technology. ${ }^{1}$ Clearly, $\mathrm{H}_{2}$ production-of which purification constitutes a major step-is vital in the eventual adoption of $\mathrm{H}_{2}$ as an energy source.

Recently more than $\$ 70$ USD/barrel, petroleum prices continue an upward trend (see Figure 1a). Since both oil production and refinery capacity in the United States are approaching steady-state, but the consumption of oil is steadily increasing (see Figure 1b), U.S. dependence on foreign petroleum sources has increased substantially-from $35 \%$ to $55 \%$ since 1973 - and is projected to be as high as $68 \%$ by $2025 .^{2}$ With a growing worldwide population and the emergence of developing nations such as China and India, the demand for dwindling oil reserves will continue to rise. Finally, fossil fuels pose a substantial threat to the environment from the emission of greenhouse gases into the atmosphere, one of the leading causes presumed to be responsible for global warming. Rising global energy requirements, as well as accompanying economic and environmental implications, corroborate a genuine need to explore other energy options such as hydrogen.

\section{The Current Status of Hydrogen Production}

On a worldwide basis, 37 billion $\mathrm{kg} / \mathrm{yr}$ of hydrogen are produced via industrial processes, with steam reforming of natural gas accounting for $80 \%$ of the hydrogen generated. ${ }^{3}$ Of the total 850 billion $\mathrm{m}^{3}$ (STP)/yr of $\mathrm{H}_{2}$ supplied globally, a little over half, 450 billion $\mathrm{m}^{3}(\mathrm{STP}) / \mathrm{yr}$, is produced intentionally, while the remainder results as a by-product from petrochemical processing at refineries. Besides its potential as an energy source, hydrogen is a versatile chemical with a wide range of commercial uses. It is essential in processes developed for the removal of sulfur from petrochemicals (hydrodesulfurization), as well as for the production of syngas (a mixture composed primarily of $\mathrm{CO}$ and $\mathrm{H}_{2}$ ), ammonia, methanol and higher alcohols, urea, and hydrochloric acid. Furthermore, $\mathrm{H}_{2}$ is routinely employed as a reducing agent for metals in Fischer-Tropsch reactions, a process used to generate hydrocarbon fuels by reacting $\mathrm{H}_{2}$ and $\mathrm{CO}$ in the presence of a transition-metal catalyst, and to modify petroleum products and oils by hydrogenation or hydrocracking. ${ }^{4-8}$

In large-scale chemical plants, such as those currently used to generate $\mathrm{H}_{2}$, separation and purification operations account for at least $50 \%$, and sometimes up to $80 \%$, of the capital investment. ${ }^{9}$ Consider, for instance, that $\mathrm{H}_{2}$ obtained from steam reforming of natural gas consumes about 74 $\mathrm{MJ} / \mathrm{kg}$ of $\mathrm{H}_{2}$ at $\sim 23$ bar on a production basis of 32.2 billion $\mathrm{kg} / \mathrm{yr}$. An estimated 470 billion $\mathrm{MJ} / \mathrm{yr}$ could be saved with only a $20 \%$ improvement in the separation/purification train after the reformer. ${ }^{10}$ Saved energy translates into reduced production cost, which is synergistic with the ultimate goal of making $\mathrm{H}_{2}$ economically competitive relative to current gasoline prices. ${ }^{8}$ Whether $\mathrm{H}_{2}$ is produced from foreign or domestic fossil fuel reserves, nuclear energy, or biomass, the need will always exist for efficient ways to separate it from other diluent gases. Advanced membrane technology may prove to be the most effective means of conducting this separation step.

\section{Membrane Separation Technology}

A membrane is a thin, permeable interface that serves to separate two regions in a chemical system. In biology, the cellular membrane is a porous protecting surface that regulates the transport of molecules into or out of the cell. The net transport of small molecules across a membrane generally requires a driving force, which is provided by a gradient in chemical potential, which relates to concentration, across the membrane. In industrial chemical processes, a membrane can be used to separate compounds based on the size of the molecule, differences in solubility of the molecules in the membrane, dissociative diffusion mechanisms, or other processes.

In this issue of MRS Bulletin, we discuss five types of advanced membrane technologies: polymer, metal, silica, zeolite, and carbon. Size-sieving glassy polymer membranes can separate $\mathrm{H}_{2}$ on the basis of its small size relative to other gases. Alternatively, reverse-selective rubbery polymers can expedite the passage and, hence, removal of $\mathrm{CO}_{2}$ due to its relatively high solubility in such membranes alone or in conjunction with dissociative chemical reactions. Transition-metal membranes and their alloys can adsorb $\mathrm{H}_{2}$ molecules, dissociate the molecules into $\mathrm{H}$ atoms for transport through interstitial sites, and subsequently recombine the $\mathrm{H}$ atoms to form molecular $\mathrm{H}_{2}$ again on the opposite membrane side. Microporous amorphous silica and zeolite membranes comprising thin films on a multilayer porous support a

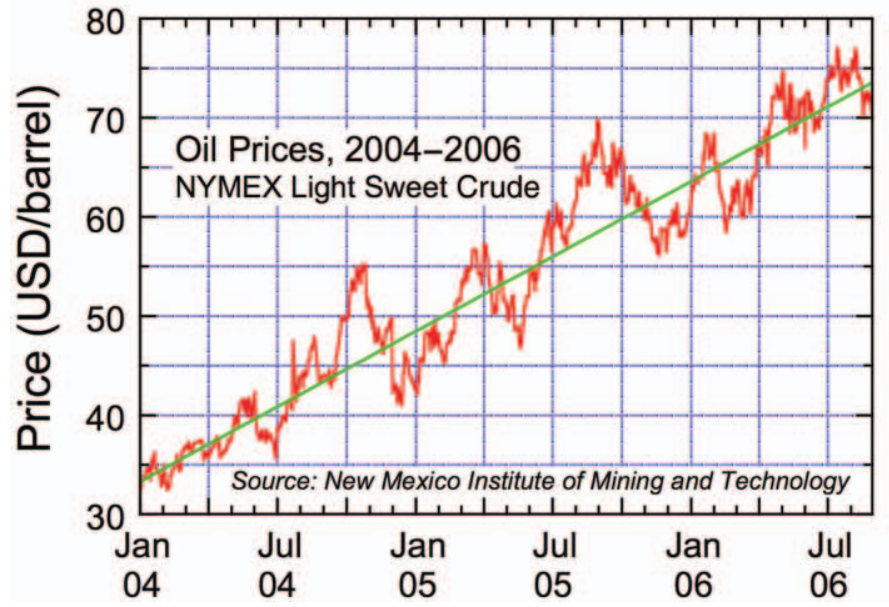

b

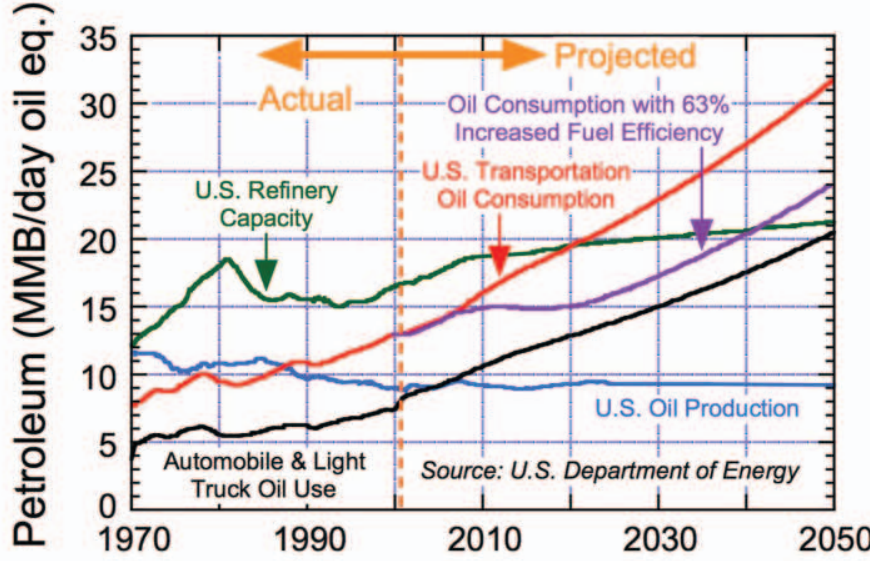

Figure 1. (a) The price of NYMEX light sweet crude oil from January 2004 to August 2006, according to the New Mexico Institute of Mining and Technology. The green line is a linear fit to the data. (Prices taken from http://octane.nmt.edu/marketplace/prices/.) (b) Long-range (actual and projected) U.S. dependence on petroleum with time, according to the U.S. Department of Energy. 
exhibit good sorption selectivity and high diffusion mobilities for $\mathrm{H}_{2}$, leading to high $\mathrm{H}_{2}$ fluxes. Finally, carbon-based membranes, including carbon nanotubes, may be viable for $\mathrm{H}_{2}$ separation on the basis of selective surface flow and molecular sieving.

\section{Polymeric Membranes for Gas Separation}

In the past decade, a considerable amount of attention has been paid to polymeric membranes in the application of gas separations. Polymeric membranes such as Polysep systems (UOP) and PRISM systems (Monsanto, Air Products and Chemicals Inc.) are currently used to recover hydrogen from refinery, petrochemical, and chemical process streams. ${ }^{3}$ Both examples are based on asymmetric membrane materials, fashioned in either spiral-wound sheet-type contactors (Polysep) or hollow fibers (PRISM) and composed of a single polymer or layers of different polymers, with the active layer being a polyimide. Typically, polymeric membranes are used in lower-temperature hydrogen recovery such as from the tail stream of a pressure swing adsorption (PSA) unit. While the relative temperature sensitivity of polymers compared with dense ceramic or transition-metal membranes is a drawback, polymeric membranes have a number of advantages. Membranes created from polymers are generally less expensive (due to the abundance and price of precursor materials), easier to process, and more mechanically tunable than their inorganic counterparts.

Gas permeation through a dense polymer membrane is most often described with the solution-diffusion model, given by

$$
P=D S,
$$

where $P$ is the permeability coefficient routinely expressed in Barrers:

$$
\begin{aligned}
& 1 \text { Barrer } \\
& =10^{-10} \mathrm{~m}^{3}(\mathrm{STP}) \mathrm{cm} /\left(\mathrm{cm}^{2} \mathrm{~s} \mathrm{~cm} \mathrm{Hg}\right) .
\end{aligned}
$$

Here, $D$ is the diffusion coefficient, often given in units of $\mathrm{cm}^{2} / \mathrm{s}$, and $S$ is the solubility coefficient in units of $\mathrm{cm}^{3}$ (gas)/ $\left[\mathrm{cm}^{3}\right.$ (polymer) $\left.\mathrm{cm} \mathrm{Hg}\right]$. The preferential ability of a polymer membrane to permeate one gas (A) over another gas $(\mathrm{B})$ is referred to as the ideal selectivity $\left(\alpha_{A / B}\right)$, as can be seen in the following equation:

$$
\alpha_{\mathrm{A} / \mathrm{B}}=\frac{P_{\mathrm{A}}}{P_{\mathrm{B}}}=\frac{D_{\mathrm{A}} S_{\mathrm{A}}}{D_{\mathrm{B}} S_{\mathrm{B}}} .
$$

The ideal selectivity can also be defined as the product of the diffusivity selectivity and the solubility selectivity of gases $A$ and $\mathrm{B}$. The diffusivity selectivity $\left(D_{\mathrm{A}} / D_{\mathrm{B}}\right)$ is governed by the size difference of penetrant gases and the size-sieving ability of a polymer material. An important factor that influences the diffusivity selectivity is the available free volume, voids not occupied by polymer chains at nanoscale dimensions through which penetrant gases migrate. In a polymer possessing relatively little free volume, as in the case of glassy polymers, only gas molecules able to fit within existing void regions can diffuse through the membrane. The diffusivity selectivity is also sensitive to temperature conditions: an increase in temperature tends to enlarge void spaces and increase the polymer free volume, thereby increasing the diffusion coefficient of penetrant gases. Solubility selectivity $\left(S_{\mathrm{A}} / S_{\mathrm{B}}\right)$, on the other hand, is governed by the solubility of gas A relative to the solubility of gas B in the polymer. Typically, solubility increases with increasing size and condensability of a gas penetrant, but decreases with increasing temperature due to reduced chemical interactions.

Glassy polymers $\left(T_{\mathrm{g}}>T_{\text {operating }}\right)$ are dominated by diffusivity selectivity and thus are often employed to remove lighter gases such as $\mathrm{H}_{2}$, whereas rubbery polymers $\left(T_{\mathrm{g}}<T_{\text {operating }}\right)$ are dominated by solubility selectivity and are therefore often used to remove heavier gases like $\mathrm{CO}_{2}$. Here, $T_{\mathrm{g}}$ denotes the glass-transition temperature of the polymer. As can be seen in Figure 2, polymeric membranes are generally subject to an upper bound, or tradeoff, between selectivity and permeability or flux. ${ }^{11,12}$ Furthermore, Figure 2a shows why glassy polymers are often preferred over rubbery materials for $\mathrm{H}_{2}$-specific separations, given the desire for high productstream purity, which is a function of the selectivity. Conversely, Figure 2b illustrates why reverse-selective rubbery polymers are preferred for $\mathrm{CO}_{2}$ removal. The cutting edge of polymeric membrane research takes place when materials are identified or developed that can break the upper limit and achieve both high selectivity and high permeability.

\section{Polymeric Membranes for $\mathrm{H}_{2}$ Permselective Separation}

In the first article in this issue, Perry et al. discuss the historical development of polymeric membranes for hydrogen separation, followed by a detailed mathematical treatment of the diffusivity and solubility parameters involved. They introduce the concepts of "hydrogen-selective" membranes, which allow hydrogen to pass through based on its small size, and "hydrogen-rejective" membranes, which
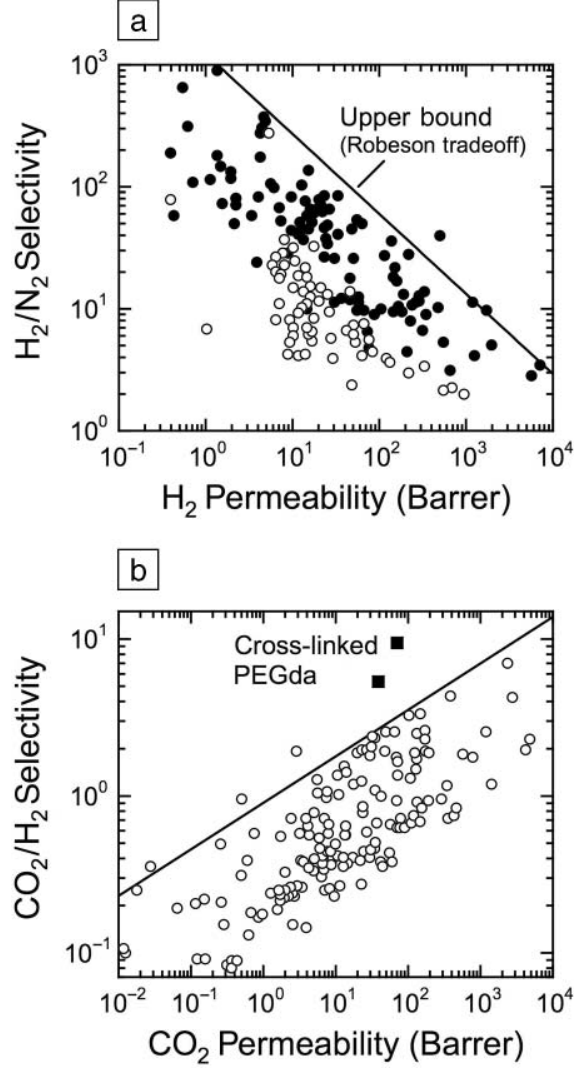

Figure 2. Relationships between (a) $\mathrm{H}_{2} / \mathrm{N}_{2}$ selectivity and $\mathrm{H}_{2}$ permeability ${ }^{11,12}$ (adapted from Reference 12 and reproduced with permission from the American Chemical Society) and (b) $\mathrm{CO}_{2} / \mathrm{H}_{2}$ selectivity and $\mathrm{CO}_{2}$ permeability ${ }^{23}$ over a wide range of polymers. In (a), rubbery and glassy polymers are depicted by open and filled symbols, respectively, whereas such delineation is not made in (b). The empirical upper bound known as the Robeson tradeoff is identified by the solid line in (a) and (b). Highly $\mathrm{CO}_{2}$-selective polyether (PEGda) membranes are identified by filled squares in (b).

favor the passage of higher-solubility molecules such as $\mathrm{CO}_{2}$ through the membrane while blocking the less-soluble $\mathrm{H}_{2}$ molecules. As mentioned previously, glassy polymers are often used for the separation of $\mathrm{H}_{2}$ and $\mathrm{CO}_{2}$ due to their ability to sieve penetrant gases on the basis of molecular size-and more specifically, the molecular kinetic diameter (see Table I). Since $\mathrm{H}_{2}$ and $\mathrm{CO}_{2}$ do not vary significantly in size and since $\mathrm{CO}_{2}$ has a tendency to be readily soluble in some polymers, separation of these two gases can often be difficult. Furthermore, depending upon the chain structure of a given polymer, $\mathrm{CO}_{2}$ can act as a plasticizing agent, effectively 


\section{Table I: Light Gas Molecules Commonly Found in $\mathrm{H}_{2}$ Purification Feed Streams and Their Kinetic Diameters. ${ }^{10}$}

\begin{tabular}{cc}
\hline Molecule & $\begin{array}{c}\text { Kinetic sieving } \\
\text { diameter (nm) }\end{array}$ \\
$\mathrm{He}$ & 0.260 \\
$\mathrm{H}_{2}$ & 0.289 \\
$\mathrm{NO}$ & 0.317 \\
$\mathrm{CO}_{2}$ & 0.330 \\
$\mathrm{Ar}$ & 0.340 \\
$\mathrm{O}_{2}$ & 0.346 \\
$\mathrm{~N}_{2}$ & 0.364 \\
$\mathrm{CO}$ & 0.376 \\
$\mathrm{CH}_{4}$ & 0.380 \\
\hline
\end{tabular}

reducing the polymer $T_{\mathrm{g}}$ and increasing chain mobility, thus increasing its passage through the expanded free volume. As a result, $\mathrm{H}_{2} / \mathrm{CO}_{2}$ selectivity only varies between 0.5 and 2.5 over a wide range of polymers. $^{13}$

Despite these findings, novel material advances have been made that have resulted in higher $\mathrm{H}_{2} / \mathrm{CO}_{2}$ selectivities. One such study examined the addition of alkyl groups onto novel poly(aryl ether ketone)s at $30^{\circ} \mathrm{C}$ and $100^{\circ} \mathrm{C}$. Inevitably, the addition of alkyl groups in the polymer backbone inhibits chain packing and therefore increases the free volume available for molecular transport, resulting in higher gas permeabilities. Wang et al. ${ }^{14}$ found that with increasing alkyl group sizes, the permeabilities of $\mathrm{H}_{2}$ and $\mathrm{CO}_{2}$ both increased, but the selectivity between the two gases decreased. Interestingly, however, by increasing the temperature to $100^{\circ} \mathrm{C}$, the $\mathrm{H}_{2} / \mathrm{CO}_{2}$ selectivity of the polymers likewise increases, along with appreciably improved $\mathrm{H}_{2}$ permeabilities.

A considerable amount of work has been conducted with polyimides and their derivatives, largely because of their high $T_{\mathrm{g}}$ and tight chain packing. A study of interest that involves outside-the-box thinking was performed by exposing polybenzimidazole $\left(T_{\mathrm{g}}=435^{\circ} \mathrm{C}\right)$ to temperature ranges that are not normally examined in routine gas transport studies. ${ }^{15}$ Pure- and mixed-gas permeabilities have been measured up to $340^{\circ} \mathrm{C}$, a temperature at which methanol reforming is usually conducted. For pure gases, the permeability of $\mathrm{H}_{2}$ reached a maximum of 18 Barrer (at $\sim 250^{\circ} \mathrm{C}$ ), which is relatively low. The corresponding $\mathrm{H}_{2} / \mathrm{CO}_{2}$ selectivity is, however, reported to be as high as 20 .

While research has been conducted with poly(amide-imide) block copolymers, ${ }^{16}$ the emerging concept of polyimide mixed-matrix composite materials has provided some promising results in gas permeation studies. Yong et al. ${ }^{17}$ reported that combinations of polyimide $\left(\right.$ Matrimid $^{\circledR}$ ), zeolite materials, and 2,4,6triaminopyrimidine (TAP) at $35^{\circ} \mathrm{C}$ yield relatively good $\mathrm{He} / \mathrm{CO}_{2}$ selectivity results (He is often used to emulate $\mathrm{H}_{2}$ due to its comparable size and inert nature). While the permeabilities are relatively low, the results illustrate that the incorporation of particles typically used for size-sieving $\mathrm{H}_{2}$ can generate a composite material (see Figure 3) capable of improved selectivity. Smaihi et al. ${ }^{18}$ generated hybrid imidesiloxane systems containing silica particles to achieve both high $\mathrm{H}_{2}$ permeabilities and selectivities. Other noteworthy materials advances include polymer laminates such as a multilayer polysulfone/silicone rubber composite membrane yielding a high $\mathrm{H}_{2} / \mathrm{N}_{2}$ selectivity at $50^{\circ} \mathrm{C}_{;}^{19}$ incorporation of a poly(ethylene oxide) layer into a polysulfone/silicone rubber composite, resulting in a $\mathrm{H}_{2} / \mathrm{N}_{2}$ selectivity that is higher than the selectivity of any one of the integrated components at $35^{\circ} \mathrm{C},{ }^{20}$ and alumina-supported styrene divinylbenzene with high $\mathrm{H}_{2} / \mathrm{CH}_{4}$ selectivities. ${ }^{21}$ Unfortunately, none of these studies provide $\mathrm{CO}_{2}$
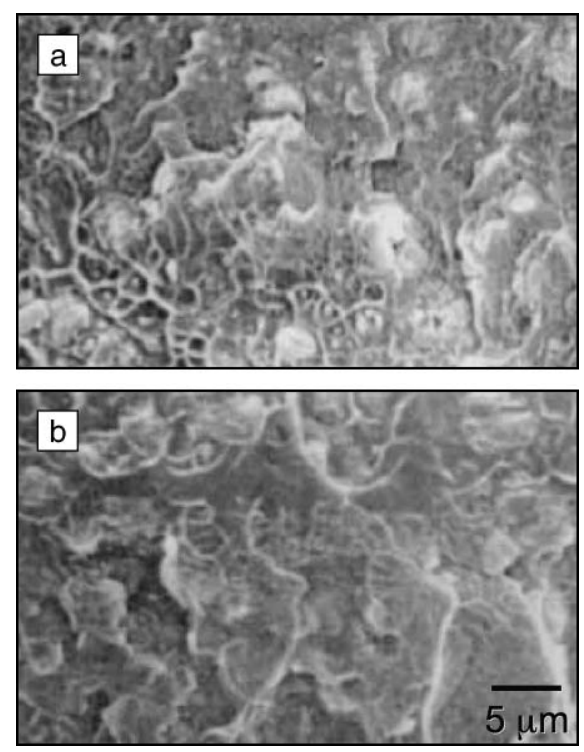

Figure 3. Scanning electron microscopy cross sections of (a) a Matrimid ${ }^{\circledR} / 4 A$ zeolite (0.38-nm pore size)/TAP (1.00/0.43/0.21 by weight) composite membrane and (b) a Matrimid ${ }^{\circledR} / 13 X$ zeolite (0.74- $\mathrm{nm}$ pore size)/TAP (1.00/0.43/0.14 by weight) composite membrane, with $\mathrm{He} / \mathrm{N}_{2}$ selectivities of 1282 and 575, respectively. (Adapted from Reference 17 and reproduced with permission from Elsevier Science.) data, so their overall value remains speculative at this point.

\section{Polymeric Membranes for $\mathrm{CO}_{2}$ Permselective Separation}

Carbon dioxide is a highly permeable gas, largely because it is an acid gas with a quadrupolar moment and high solubility in a number of polymers, particularly rubbery polymers that possess polar chemical species. Such reverse-selectivity can be used to promote $\mathrm{CO}_{2}$ migration into the permeate stream, leaving $\mathrm{H}_{2}$ pressurized in the rententate stream. The net result is removal of the $\mathrm{CO}_{2}$ contaminant and recovery of the $\mathrm{H}_{2}$ product at high pressure, thereby eliminating the need for costly $\mathrm{H}_{2}$ recompression prior to use or storage. These membranes have resulted in $\mathrm{CO}_{2} / \mathrm{H}_{2}$ selectivities as high as $\sim 10$ in a polyphosphazene composed of poly(dichlorophosphazene) modified with 2-(2-methoxyethoxy)ethanol. ${ }^{22}$ Similar $^{23,24}$ and, depending on temperature, even higher ${ }^{24,25} \mathrm{CO}_{2} / \mathrm{H}_{2}$ selectivities have been measured in cross-linked poly(ethylene glycol) diacrylate (PEGda) membranes, as shown in Figure $2 b$.

In the second article in this issue, Hägg and Quinn examine one type of hydrogenrejective membrane referred to as a polymeric facilitated transport membrane. These membranes selectively permeate $\mathrm{CO}_{2}$ by means of a reversible chemical reaction between the penetrant gas and the membrane material. In addition, the membrane provides a barrier to $\mathrm{H}_{2}$ permeation. A wide range of polymeric materials have been investigated, including ion-exchange resins, hydrophilic polymers blended with $\mathrm{CO}_{2}$-reactive salts, polyelectrolytes, fixed-site carrier polymers, and biologically inspired materials.

Some glassy, high-free-volume polymers are inherently $\mathrm{CO}_{2}$-selective, but their more attractive characteristic is their unusually high gas permeabilities. Poly(1-trimethylsilyl-1-propyne) (PTMSP), poly(1-methyl-1-pentyne) (PMP), and poly(tert-butylacetylene) (PTBA), all substituted polyacetylenes, possess $\mathrm{H}_{2}$ permeabilities of $\sim 19,000$ Barrer, 5800 Barrer, and 300 Barrer, respectively, but their $\mathrm{CO}_{2} / \mathrm{H}_{2}$ selectivities are all only $\sim 2$ at $25^{\circ} \mathrm{C} .{ }^{26,27}$ A random copolymer composed of tetrafluoroethylene and poly[2,2bis(trifluoro-methyl)-4,5-difluoro-1,3dioxole] (TFE/BDD, 87/13 mol basis), as well as Teflon ${ }^{\circledR}$, both exhibit $\mathrm{H}_{2}$ permeabilities of over 3000 Barrer. However, they exhibit even lower $\mathrm{CO}_{2} / \mathrm{H}_{2}$ selectivities (slightly greater than 1 at $25^{\circ} \mathrm{C}$ ). ${ }^{28,29}$ Most of these membranes, along with polydimethylsiloxane (PDMS), are better suited for the removal of larger organic vapors 
over light gases such as hydrogen, ${ }^{30}$ although PDMS does exhibit a $\mathrm{CO}_{2} / \mathrm{H}_{2}$ selectivity of $\sim 4.3$ at $35^{\circ} \mathrm{C} .{ }^{31}$

\section{Inorganic Membranes for $\mathrm{H}_{2}$ Purification}

Much effort has recently been devoted to the synthesis of inorganic membranes because of their potential applications in the domains of gas separation, pervaporation, and reverse osmosis, as well as in the development of chemical sensors and catalytic membranes. ${ }^{32-36}$ Inorganic membranes, which possess good thermal stability and chemical inertness, enjoy several important advantages over polymer membranes for many industrial applications. Improvements continue to focus on areas of membrane integrity and manufacturing costs.

\section{Alloys and Metals}

Metallic materials are of great interest for hydrogen-selective membranes. ${ }^{10}$ The article by Sholl and Ma describes metal membranes for high-temperature applications. The physical mechanism of $\mathrm{H}_{2}$ permeation through metal membranes is quite different from porous membranes: metal membranes function by adsorbing and dissociating gaseous $\mathrm{H}_{2}$ on the metal surface exposed to the feed stream and subsequent diffusion of atomic $\mathrm{H}$ through interstitial sites in the metal. Recombination of atomic $\mathrm{H}$ into $\mathrm{H}_{2}$ on the downstream membrane side completes the transport of $\mathrm{H}_{2}$ across the membrane. Because of this mechanism, metal membranes can achieve essentially perfect selectivity for $\mathrm{H}_{2}$ when exposed to gas mixtures, because transport of species other than hydrogen through the membrane is restricted to defects in the film. Effective membranes can be prepared by depositing thin metal films on macroporous supports. These membranes can be $100 \%$ selective toward hydrogen since hydrogen is transported in dissociated form, which yields ultrapure hydrogen with little or no greenhouse gas contamination. Despite such performance, porous membranes can still be useful to drive the reaction. More work is needed to explore practical opportunities in this area. Of the metals currently of interest, $\mathrm{Pd}$ remains the most promising for $\mathrm{H}_{2}$-selective membranes, even with its mechanical limitations, including embrittlement, cracks, pinhole film defects, delamination, and sulfur sensitivity. 10,32,37-42

Furthermore, for Pd membranes to be economically attractive in $\mathrm{H}_{2}$ separations, they have one major shortcoming that must be addressed prior to their wide-scale implementation in industrial processes: their flux must be improved by a factor of 2-4 for use in steam reformers or water-gas shift (WGS) reactors. ${ }^{10}$ As a result, current research is focused on the consistent preparation of thin Pd films, measuring $\sim 5 \mu \mathrm{m}$ thick, that can still afford high selectivity. Thin Pd membranes deposited on porous supports, such as porous alumina or porous metal, are able to withstand the operating conditions typical of $\mathrm{H}_{2}$ manufacture processes. Sol-gel processing ${ }^{43}$ and chemical vapor deposition (CVD) $39,40,44$ have thus far been the methods of choice to prepare such thin films. Sol-gel modification provides good selectivity and permeability, in contrast to CVD methods, which yield membranes with reduced permeability but enhanced selectivity. The sol-gel method, however, suffers from poor reproducibility. A variety of synthetic methods have been reported in addition to those already listed, ${ }^{44,45}$ including electroless plating, ${ }^{10,45-49}$ where films exhibit high permeances for long operational times while retaining $\mathrm{H}_{2} / \mathrm{N}_{2}$ selectivities on the order of 1000 .

\section{Silicas and Zeolites}

High-temperature porous membranes (e.g., silica, silicalites, and zeolites) have also been investigated for applications in steam reforming, ${ }^{51,52}$ dry reforming, ${ }^{53-55}$ and WGS reactions. ${ }^{56,57}$ These materials eliminate the need for scarce precious metals. In addition, they are less expensive and exhibit higher permeances than Pd-based membranes. Moreover, they are inert to $\mathrm{H}_{2}$ embrittlement. Verweij et al. discuss microporous amorphous silica and zeolite membranes synthesized as thin films on a multilayer porous support. The membranes possess a network of connected micropores measuring $\sim 0.5 \mathrm{~nm}$ in diameter. Favorable combinations of sorption selectivity and diffusion mobility in the membrane materials lead to high $\mathrm{H}_{2}$ fluxes and good selectivity with respect to other gases. The membranes also show potential for application in $\mathrm{H}_{2}$ separation under harsh conditions. Amorphous silica membranes exhibit very high $\mathrm{H}_{2}$ fluxes because they can be made very thin, but all-silica MFI-type zeolite (termed silicalite) membranes are expected to demonstrate better operational stability. To make the membranes a viable option, improvements are needed to reduce the occurrence of membrane defects, decrease manufacturing costs, and enhance reproducibility and operational stability.

To date, the most promising results for a membrane separation with steam reforming have been achieved with a silica zirconia composite membrane prepared by sol-gel coating. ${ }^{51}$ However, the presence of water vapor may significantly affect the performance of these silica membranes over time, particularly if operated at relatively low temperatures. ${ }^{10}$ Recent studies on silica-based zeolite membranes (see Figure 4) have confirmed that $\mathrm{H}_{2} \mathrm{O}$ adsorption at temperatures $>100^{\circ} \mathrm{C}$ interferes with $\mathrm{H}_{2}$ selectivity by enhancing $\mathrm{CO}_{2}$ permeance. ${ }^{58}$ Microporous silicas are very promising due to their low cost, high stability, and high permeance. Recently, these membranes have also yielded exceptional $\mathrm{H}_{2}$ selectivities, with the best $\mathrm{H}_{2} / \mathrm{N}_{2}$ selectivities exceeding 10,000 for membranes prepared by CVD. ${ }^{10,58-61}$ An extension of silica membrane research is the development of hybrid metal-coated silica systems, such as the Al-coated $\mathrm{SiO}_{2}$ permselective membranes reported by Oyama. ${ }^{61}$ They are likewise prepared by CVD of a thin $\mathrm{SiO}_{2}$ layer on a porous alumina substrate, resulting in a non-continuous network of solubility sites. The submicrometer-thick silica-on-alumina composite motif uses progressive size gradation, thereby promoting enhanced permeability of hydrogen over $\mathrm{CO}_{2}, \mathrm{~N}_{2}, \mathrm{CO}$, and $\mathrm{CH}_{4}$.

Another method for avoiding costly and fragile $\mathrm{Pd}$ for $\mathrm{H}_{2}$ purification relies on the use of nanoporous membranes. Zeolite membranes in particular combine pore size and shape selectivity with the inherent mechanical, thermal, and chemical stability necessary for long-term operation. The effective pore size distribution of the zeolite membrane, and hence its separation performance, is intrinsically governed by the choice of the zeolitic phase. ${ }^{62-65}$ This applies when molecularsize-exclusion sieving is dominant and no other diffusion pathways bypass the network of well-defined zeolitic channels (otherwise, viscous flow through grain boundaries prevails). The optimum thickness of the zeolite film is always a compromise between separation performance and overall transmembrane flux and should be tailored to the needs of the application envisioned. Very thin $(\sim 0.5 \mu \mathrm{m})$ $H$-galloaluminosilicate ZSM-5 type (MFI) membranes on alumina have recently been synthesized ${ }^{66}$ and found to exhibit high fluxes [He permeance of $\sim 80 \times 10^{-7}$ $\left.\mathrm{mol} /\left(\mathrm{m}^{2} \mathrm{~s} \mathrm{~Pa}\right)\right]$ coupled with separation factors essentially in the Knudsen diffusion regime $\left(\mathrm{He} / \mathrm{SF}_{6} \approx 0.9\right.$ Knudsen factor). Large-surface-area MFI membranes have been grown with a high success rate and exhibit good selectivity characteristics $\left(\mathrm{H}_{2} / \mathrm{SF}_{6}>3\right.$ Knudsen factor) but low $\mathrm{H}_{2}$ permeance, on the order of $1.510^{-8}$ $\mathrm{mol} /\left(\mathrm{m}^{2} \mathrm{~s} \mathrm{~Pa}\right){ }^{67}$

Due to the need for carbon sequestration associated with $\mathrm{H}_{2}$ production from fossil fuels, zeolite membranes selective 


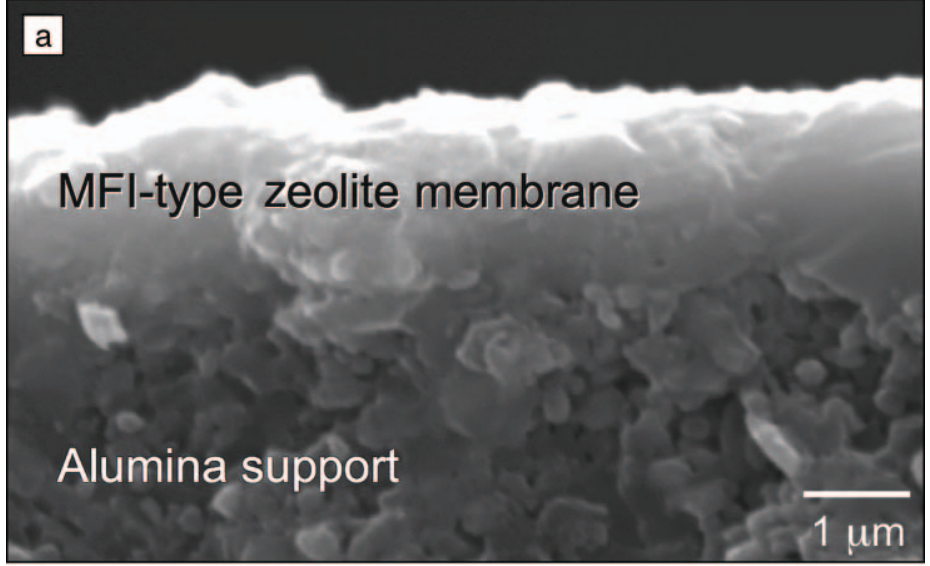

$\mathrm{b}$

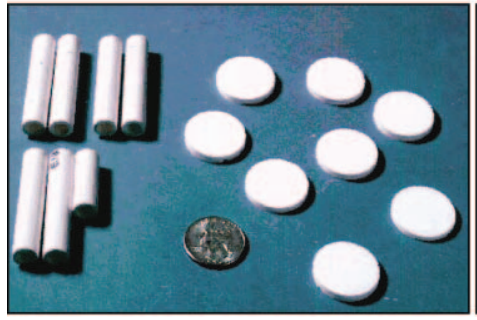

C

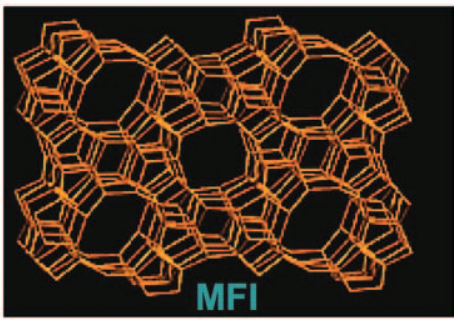

Figure 4. (a) Scanning electron microscopy cross section of an MFl-type zeolite membrane on an alumina support. ${ }^{58}$ (b) The membrane ceramic supports ${ }^{58}$; (c) the MFI structure. (Adapted from the IZA database website, www.iza-structure.org/databases.)

for $\mathrm{CO}_{2}$ gas separations have also been studied and include the faujasite (FAU) and the silica/aluminophosphate (SAPO4) framework families. For example, Dong and co-workers ${ }^{68}$ reported that the addition of water vapor to the $\mathrm{CO}_{2} / \mathrm{N}_{2}$ feed gas drastically reduced $\mathrm{CO}_{2}$ and $\mathrm{N}_{2}$ permeances and altered the membrane selectivity at low temperature $\left(<80^{\circ} \mathrm{C}\right)$, but enhanced $\mathrm{CO}_{2}$ selectivity at elevated temperature $\left(140-200^{\circ} \mathrm{C}\right)$. Noble and Falconer ${ }^{69}$ have likewise demonstrated that their SAPO- 4 zeolite membranes can be used to separate $\mathrm{CO}_{2}$ from $\mathrm{CH}_{4}$ under a variety of pressures and temperatures, with high selectivities at $30 \mathrm{~atm}$ and $50^{\circ} \mathrm{C}$.

\section{Carbon-Based Membranes}

In her article, Pietraß discusses the use of carbon membranes and carbon nanotubes (CNTs) as hydrogen separation devices. Carbon membranes have been prepared as unsupported or supported materials. Typical precursors are organic polymers that are converted to pure carbon materials by treatment at high temperature in an inert atmosphere (carbonization). Among the unsupported membranes, capillary tubes or hollow fibers and flat membranes have been fabricated to date.
Selective surface flow (SSFTM) membranes were introduced in 1993 by Rao and Sircar. ${ }^{70}$ These porous carbon membranes are formed by cross-linking and subsequent carbonization of poly(vinylidene chloride)-acrylate terpolymer latex polymer. The permeability of hydrogen in a mixture with hydrocarbons was reduced by several orders of magnitude over that of pure hydrogen, indicating that hydrocarbon-selective adsorption hindered the pore diffusion of hydrogen, thus making these membranes extremely promising for hydrogen separation. The advantages of these membranes are multifold. Since adsorption occurs on the highpressure side, the partial pressure of the component to be adsorbed can be low, and the partial pressure gradient across the membrane does not need to be high to achieve satisfactory separation. The driving force for mass transfer across the membrane is the difference in the concentration of the adsorbed species.

In addition, carbon nanotubes are being investigated for possible use in hydrogen separation. The unique porous structure of an array of CNTs that can be millimeters long at diameters of molecular dimensions has prompted studies to investigate transport through these tubes. The smoothness of the interior in defect-free nanotubes gives rise to greater transport capacity than conventional carbon-based membranes. Hydrogen separations are expected to be effective for very small nanotube diameters.

\section{Conclusions}

Worldwide, various membranes composed of diverse materials have been and continue to be studied and optimized for the robust and economically efficient large-scale production of $\mathrm{H}_{2}$. Each type of membrane possesses strengths and current weaknesses. ${ }^{8}$ However, strides are being continually reported to improve each membrane type to eventually meet the $\mathrm{H}_{2}$ energy goals established by the U.S. Department of Energy and its global counterparts.

While polymeric membranes have come a long way over the past decade, it is obvious that more work is required to create competitive technologies that will help reduce production costs for a sustainable hydrogen economy. In the short term, polymeric membranes must be further developed for either $\mathrm{H}_{2}$ - or $\mathrm{CO}_{2}$-selective applications. Ideally, $\mathrm{H}_{2}$-selective membranes should exhibit $\mathrm{H}_{2} / \mathrm{CO}_{2}$ selectivities that exceed $15-20$ at $200^{\circ} \mathrm{C}$, which is the current range for commercial membranes, whereas $\mathrm{CO}_{2}$-selective membranes (which could likewise benefit air revitalization technologies) should target $\mathrm{CO}_{2} / \mathrm{H}_{2}$ selectivities that are double the current commercial membranes. Greater stability and improved performance at elevated temperatures (e.g., at syngas conditions of $200^{\circ} \mathrm{C}$ ) would significantly benefit the involvement of polymer membranes in commercial $\mathrm{H}_{2}$ activities. Long-term research strategies should be examined for mixed-matrix membranes and the development of organic-inorganic hybrid materials that could yield unexpected, but highly desirable, properties. ${ }^{71}$ Polymeric membranes possess a great deal of potential, provided novel concepts are conceived to meet both short-term and long-term hydrogen separation goals.

Inorganic membranes hold the potential for full and near-term industrial implementation due to their tunable nature and high-temperature/high-pressure stability. However, a few materials-related hurdles remain. Concerns associated with these materials include increasing the selectivity and flux for metal membranes as well as reproducibility in porous membranes. Compared with organic membranes, inorganic membranes are currently expensive to manufacture. Introduction into large-scale production facilities is, however, anticipated to result in more competitive costs approaching $\$ 1100 \mathrm{USD} / \mathrm{m}^{2}$. 
The marriage of $\mathrm{H}_{2}$-selective membranes with advances in materials-related nanotechnology, including nanotube synthesis and designer nanoporosity, holds tremendous promise for the development of stable inorganic membranes capable of achieving the gas separation goals necessary to ultimately realize a hydrogen economy.

\section{Acknowledgments}

Sandia is a multiprogram laboratory operated by Sandia Corporation, a Lockheed Martin Company, for the U.S. Department of Energy's National Nuclear Security Administration under contract DE-AC04-94AL85000. T. Nenoff thanks the DOE's Hydrogen, Fuel Cells, \& Infrastructure Technologies Program for continued support. R.J. Spontak gratefully acknowledges support from the U.S. DOE under contract DE-FG02-99ER14991, the Research Council of Norway under the NANOMAT Program, and the STC Program of the National Science Foundation (CHE-9876674).

\section{References}

1. Hydrogen, Fuel Cells $\mathcal{E}$ Infrastructure Technologies Program. Multi-Year Research, Development and Demonstration Plan. Planned Program Activities for 2003-2010 (U.S. Department of Energy, Washington, DC, 2003).

2. S.G. Chalk and J.J. Romm, Chem. E Eng. News 83 (34) (2005) p. 30.

3. The Hydrogen Economy: Opportunities, Costs, Barriers, and RED Needs, Committee on Alternatives and Strategies for Future Hydrogen Production and Use, National Research Council, National Academy of Engineering (National Academy Press, Washington, DC, 2005).

4. Kirk-Othmer Concise Encyclopedia of Chemical Technology, 4th ed. (John Wiley \& Sons, New York, 1999)

5. “Gas Processing 2002," Hydrocarbon Process. (May 2002).

6. "Petrochemical Processes 2003," Hydrocarbon Process. (March 2003).

7. R.A. Meyers, Handbook of Petroleum Refining Processes, 3rd ed. (McGraw-Hill, New York, 2004)

8. H.A. Wittcoff, B.G. Reuben, and J.S. Plotkin, Industrial Organic Chemicals, 2nd ed. (John Wiley \& Sons, Hoboken, NJ, 2004).

9. J.M. Prausnitz, R.N. Lichtenthaler, and E.G. de Azevedo, Molecular Thermodynamics of Fluid Phase Equilibria, 3rd ed. (Prentice Hall, Englewood Cliffs, NJ, 1999).

10. J.A. Ritter and A.D. Ebner, DOE/ITP/ Chemicals \& Chemicals Industry Vision 2020 Technology Partnership (December 2005); J.A. Ritter and A.D. Ebner, Sep. Sci. Technol (2006) submitted.

11. L. Robeson, J. Membr. Sci. 62 (1991) p. 165. 12. B.D. Freeman, Macromolecules 32 (1999) p. 375 .

13. C.J. Orme, M.L. Stone, M.T. Benson, and E.S. Peterson, Sep. Sci. Technol. 38 (2003) p. 3225. 14. Z.G. Wang, T.L. Chen, and J.P. Xu,
Macromolecules 33 (2000) p. 5672.

15. D.R. Pesiri, B. Jorgensen, and R.C. Dye, J. Membr. Sci. 218 (2003) p. 11.

16. M. Langsam and D.V. Laciak, J. Polym. Sci., Part A: Polym. Chem. 38 (2000) p. 1951.

17. H.H. Yong, N.C. Park, Y.S. Kang, J. Won, and W.N. Kim, J. Membr. Sci. 188 (2001) p. 151. 18. M. Smaihi, J.C. Schrotter, C. Lesimple, I. Prevost, and C. Guizard, I. Membr. Sci. 161 (1999) p. 157

19. X.S. Feng, P.H. Shao, R.Y.M. Huang, G.L. Jiang, and R.X. Xu, Sep. Purif. Technol. 27 (2002) p. 211.

20. Z. Ye, Y. Chen, H. Li, G. He, and M. Deng, Mater. Chem. E Phys. 94 (2005) p. 288.

21. J. Hradil, V. Krystl, P. Hrabanek, B. Bernauer, and M. Kocirik, React. Funct. Polym. 61 (2004) p. 3.

22. C.J. Orme, M.K. Harrup, T.A. Luther, R.P. Lash, K.S. Houston, D.H. Weinkauf, and F.F. Stewart, J. Membr. Sci. 186 (2001) p. 249.

23. N.P. Patel, A.C. Miller, and R.J. Spontak, Adv. Mater. 15 (2003) p. 729; N.P. Patel, A.C. Miller, and R.J. Spontak, Adv. Funct. Mater. 14 (2004) p. 699

24. N.P. Patel, C.M. Aberg, A.M. Sanchez, M.D. Capracotta, J.D. Martin, and R.J. Spontak, Polymer 45 (2004) p. 5941.

25. H.Q. Lin, E. van Wagner, B.D. Freeman, L.G. Toy, and R.P. Gupta, Science 311 (2006) p. 639.

26. A. Morisato and I. Pinnau, J. Membr. Sci. 121 (1996) p. 243

27. A. Morisato, H.C. Shen, S.S. Sankar, B. Freeman, I. Pinnau, and C.G. Casillas, J. Polym. Sci., Part B: Polym. Phys. 34 (1996) p. 2209.

28. T.C. Merkel, V. Bondar, K. Nagai, B.D. Freeman, and Y.P. Yampolskii, Macromolecules 32 (1999) p. 8427.

29. I. Pinnau and L.G. Toy, J. Membr. Sci. 109 (1996) p. 125.

30. I. Pinnau and Z. He, J. Membr. Sci. 244 (2004) p. 227.

31. T.C. Merkel, V.I. Bondar, K. Nagai, B.D. Freeman, and I. Pinnau, I. Polym. Sci., Part B: Polym. Phys. 38 (2000) p. 415.

32. J.N. Armor, J. Membr. Sci. 147 (1998) p. 217. 33. J. Caro, M. Noack, P. Kolsch, and R. Schafer, Microporous Mesoporous Mater. 38 (2000) p. 3.

34. A.S.T. Chiang and K.-J. Chao, J. Phys. E Chem. Solids 62 (2001) p. 1899

35. M. Noack, P. Kolsch, R. Schafer, P. Toussaint, and J. Caro, Chem. Eng. Technol. 25 (2002) p. 221.

36. S.G. Thoma, D.E. Trudell, F. Bonhomme, and T.M. Nenoff, Microporous Mesoporous Mater. 50 (2001) p. 33

37. A.-G. Collot, "Prospects for hydrogen from coal," IEA Clean Coal Center (2003).

38. S. Uemiya, Top. Catal. 29 (2004) p. 79.

39. E. Kikuchi, Catal. Today 56 (2000) p. 97

40. E. Kikuchi, Y. Nemoto, M. Kajiwara, S. Uemiya, and T. Kojima, Catal. Today 56 (2000) p. 75 .

41. S.N. Paglieri and J.D. Way, Sep. Purif. Methods 31 (2002) p. 1.

42. K.S. Rothenberger, Y.H. Ma, F. Bustamante, R.P. Killmeyer, I.P. Mardilovich, B.D. Morreale, R.M. Enick, and A.V. Cugini, J. Membr. Sci. 224 (2004) p. 55.
43. H.B. Zhao, G.X. Xiong, J.H. Gu, S.S. Sheng, H. Bauser, N. Stroh, and K. Pflanz, Catal. Today 25 (1995) p. 237.

44. G. Barbieri, V. Violante, F.P. Dimaio, A Criscuoli, and E. Drioli, Ind. Eng. Chem. Res. 36 (1997) p. 3369

45. V. Jayaraman, Y.S. Lin, M. Pakala, and R.Y. Lin, J. Membr. Sci. 99 (1995) p. 89.

46. Y.M. Lin, G.L. Lee, and M.H. Rei, Catal. Today 44 (1998) p. 343.

47. Y.M. Lin, S.L. Liu, C.H. Chuang, and Y.T. Chu, Catal. Today 82 (2003) p. 127.

48. J.N. Keuler, L. Lorenzen, and S. Miachon, Sep. Sci. Technol. 37 (2002) p. 379.

49. L. Paturzo and A. Basile, Ind. \& Eng. Chem. Res. 41 (2002) p. 1703

50. X.L. Pan, N. Stroh, H. Brunner, G.X. Xiong, and S.S. Sheng, Sep. Purif. Technol. 32 (2003) p. 265. 51. T. Tsuru, T. Tsuge, S. Kubota, K. Yoshida, T. Yoshioka, and M. Asaeda, Sep. Sci. Technol. 36 (2001) p. 3721

52. S. Kurungot and T. Yamaguchi, Catal. Lett. 92 (2004) p. 181.

53. T. Ioannides and X.E. Verykios, Catal. Lett. 36 (1996) p. 165.

54. P. Ferreira-Aparicio, I. Rodriguez-Ramos, and A. Guerrero-Ruiz, Appl. Catal., A 237 (2002) p. 239.

55. D. Lee, P. Hacarlioglu, and S.T. Oyama, Top Catal. 29 (2004) p. 45

56. S. Giessler, L. Jordan, J.C.D. da Costa, and G.O. Lu, Sep. Purif. Technol. 32 (2003) p. 255.

57. Y. Hasegawa, K. Kusakabe, and S. Morooka, J. Membr. Sci. 190 (2001) p. 1.

58. J. Dong, W. Liu, and Y.S. Lin, AIChE J. 46 (2000) p. 1957; L. Li, K. Adams, J. Dong, and T.M. Nenoff, J. Membr. Sci. (2006) in preparation. 59. A.K. Prabhu, R. Radhakrishnan, and S.T. Oyama, Appl. Catal., A 183 (1999) p. 241.

60. A.K. Prabhu and S.T. Oyama, Chem. Lett (1999) p. 213.

61. A.K. Prabhu and S.T. Oyama, J. Membr. Sci. 176 (2000) p. 233

62. Z.A.E.P. Vroon, K. Keizer, M.J. Gilde, H. Verweij, and A.J. Burggraaf, J. Membr. Sci. 113 (1996) p. 293.

63. E.R. Geus, M.J. den Exter, and H.J. van Bekkum, Chem. Soc. Faraday Trans. 88 (1992) p. 3101.

64. W.J.W. Bakker, F. Kapteijn, J. Poppe, and J.A. Moulijn, J. Membr. Sci. 117 (1996) p. 57.

65. C. Bai, M.-D. Jia, J.L. Falconer, and R.D. Noble, J. Membr. Sci. 105 (1995) p. 79.

66. J. Hedlund, J. Sterte, M. Anthonis, A.J. Bons, B. Carstensen, N. Corcoran, D. Cox, H. Deckman, W. De Gijnst, P.-P. de Moor, F. Lai, J. McHenry, W. Mortier, J. Reinoso, and J. Peters, Microporous Mesoporous Mater. 52 (2002) p. 179. 67. M. Noack, P. Kolsch, R. Schafer, P. Toussaint, I. Sieber, and J. Caro, Microporous Mesoporous Mater. 49 (1-3) (2001) p. 25.

68. X.H. Gu, J.H. Dong, and T.M. Nenoff, Ind. Eng. Chem. Res. 44 (2005) p. 937.

69. S. Li, J.G. Martinek, J.L. Falconer, R.D. Noble, and T.Q. Gardner, Ind. Eng. Chem. Res. 44 (2005) p. 3220.

70. M.B. Rao and S. Sircar, J. Membr. Sci. 85 (1993) p. 253.

71. T.C. Merkel, B.D. Freeman, R.J. Spontak, Z. He, I. Pinnau, P. Meakin, and A.J. Hill, Science 296 (2002) p. 519 


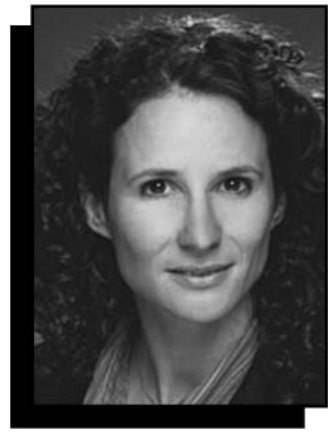

Tina M. Nenoff

Tina M. Nenoff, Guest Editor for this issue of MRS Bulletin, is a distinguished member of technical staff at Sandia National Laboratories. Nenoff earned her BA degree in chemistry in 1987 from the University of Pennsylvania. She obtained her PhD degree in 1993 at the University of California, Santa Barbara, in the Chemistry Department under the guidance of Galen D. Stucky. She then joined the staff at Sandia National Laboratories.

Nenoff's research has been directed toward the synthesis and application of novel condensed and microporous oxide phases for catalysis and separations. She is focused on defect-free inorganic thin-film membranes for $\mathrm{H}_{2}$ purification and hydrocarbon feedstock separations. Another area of focus is on the synthesis and characterization of oxide ion exchangers for the removal and fixation of radioisotopes from caustic solutions containing many competing ions.

She has published more than 100 papers in various materials science and chemistry journals and has presented at more than 50 national and international conferences. Nenoff is a

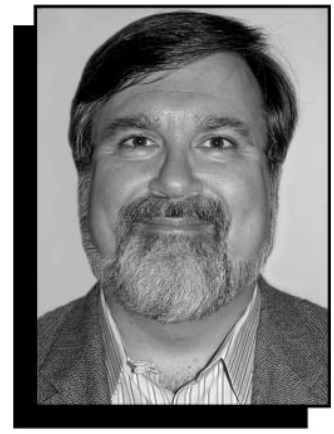

Richard J. Spontak

member of the Materials Research Society and the American Chemical Society.

Nenoff can be reached at Sandia National Laboratories, Surface and Interface Studies, PO Box 5800, MS 1415, Albuquerque, NM 87185-1415 USA; tel. 505-844-0340, fax 505-844-5470, e-mail tmnenof@sandia.gov, and URL www.sandia. gov/nenoff.

Richard J. Spontak, Guest Editor for this issue of MRS Bulletin, is an Alumni Distinguished Professor of Chemical and Biomolecular Engineering and Materials Science and Engineering at North Carolina State University. He received his $\mathrm{BS}$ and $\mathrm{PhD}$ degrees in chemical engineering from the Pennsylvania State University (1983) and the University of California, Berkeley (1988), respectively, and conducted postdoctoral research at the University of Cambridge and the Institutt for Energiteknikk (Norway) before joining the Procter \& Gamble Co. and, in 1992, NCSU.

Spontak's research focuses on nanostructured polymers and polymer nanocomposites for diverse applications, including light gas separations. His group

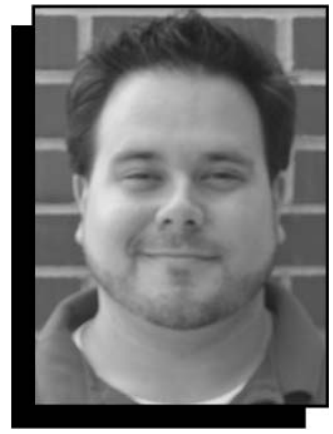

Christopher M. Aberg

has introduced crosslinked polyethers, as well as their blends and nanocomposites, as highly $\mathrm{CO}_{2}$-selective membranes. He received this year's American Chemical Society Cooperative Research Award (PMSE Division) and the International Network for Engineering Education and Research Recognition Award. Spontak currently serves or has served on the editorial boards of Macromolecules, Macromolecular Rapid Communications, Macromolecular Chemistry and Physics, and Materials Today. He has published more than 200 peer-reviewed articles, with his work being featured on 14 journal covers and one book cover.

Spontak can be reached at North Carolina State University, Department of Chemical and Biomolecular

Engineering, Centennial Campus, 911 Partners Way, Raleigh, NC 276957905 USA; tel. 919-5154200, fax 919-515-3465, and e-mail rich_spontak@ ncsu.edu.

\section{Christopher M. Aberg} is a graduate student under the advisement of Richard J. Spontak in the Department of Chemical and Biomolecular Engineering at North Carolina State

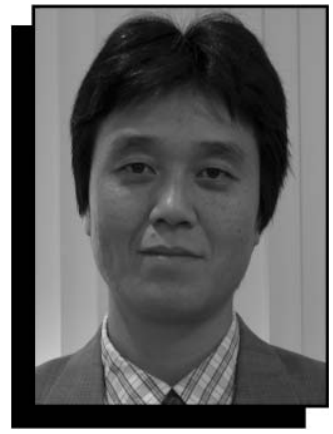

Junhang Dong

University. He expects to earn his graduate degree in December 2006.

Prior to his time at

North Carolina State University, Aberg attended the University of Maryland, Baltimore County, where he was a recipient of the nationally recognized Meyerhoff Scholarship and graduated with his bachelor's degree in chemical engineering.

Aberg's specific re-

search is on the separation of hydrogen using polymeric membranes, while his broad interest in the field is centered on environmentally conscious processing.

Aberg can be reached at North Carolina State University, Department of Chemical and Biomolecular Engineering, Centennial Campus, 911 Partners Way, Raleigh, NC 27695-7905 USA; tel. 919-601-9782 and e-mail cmaberg@ unity.ncsu.edu.

Junhang Dong is an associate professor in the Department of Chemical and Materials Engineering at the University of Cincinnati. He received his $\mathrm{PhD}$ degree in chemical engineering from Nanjing University of Technology, China, in 1995. Dong was an associate professor of chemical engineering at the New Mexico Institute of Mining and Technology

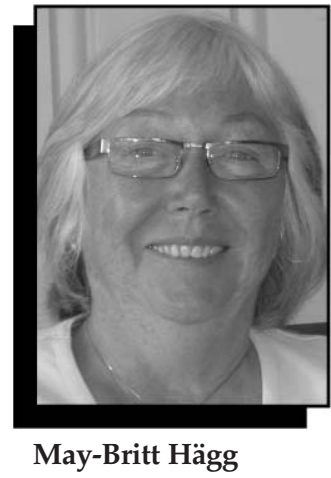

from 2005 to 2006 after serving as an assistant professor from 2001 to 2005.

His research focuses on developing microporous ceramic membranes and nanostructured solid oxide thin films and understanding their structure-property relationships for applications in advanced energy technologies.

Dong can be reached at the University of Cincinnati, Department of Chemical and Materials Engineering, Cincinnati, $\mathrm{OH} 45221$ 0012, USA; tel. 513556-3992, fax 513-5563473, and e-mail junhang.dong@uc.edu.

May-Britt Hägg is a professor at the Norwegian University of Science and Technology in the Department of Chemical Engineering, where she earned her MS and PhD degrees. Hägg has spent more than 25 years in research and lecturing. Also, she worked in industry at Statoil ASA.

She currently heads a membrane research group with a focus on materials development and membranes for gas separations, emphasizing $\mathrm{CO}_{2}$ capture and $\mathrm{H}_{2}$ separation. The research includes process development with simulations.

Hägg can be reached at NTNU, Department 


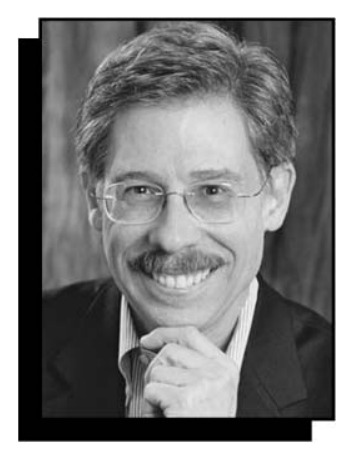

William J. Koros

of Chemical Engineering, N-7491 Trondheim, Norway; tel. 47-73594033, fax 47-73594080, and e-mail may-britt.hagg@ chemeng.ntnu.no.

William J. Koros is the Roberto C. Goizueta Chair in Chemical and Biomolecular Engineering at the Georgia Institute of Technology in Atlanta. He received his BS, MS, and $\mathrm{PhD}$ degrees in chemical engineering at the University of Texas. Afterward, Koros spent four years with DuPont. In 1977, he joined the faculty of the Chemical Engineering Department at North Carolina State University. In 1984, Koros moved to the faculty of the Department of Chemical Engineering at the University of Texas at Austin and served as department chair from 1993 to 1997. While at UT Austin, he held the Meek-Petrofina Professorship from 1986 to 1991 and the B.F. Goodrich Professorship from 1991 to 2001 . He joined the School of Chemical Engineering at Georgia Tech in 2001.

While at NCSU, Koros received the Sigma Xi Award for research accomplishments, and in 1983 he received a National Science Foundation Presidential Young

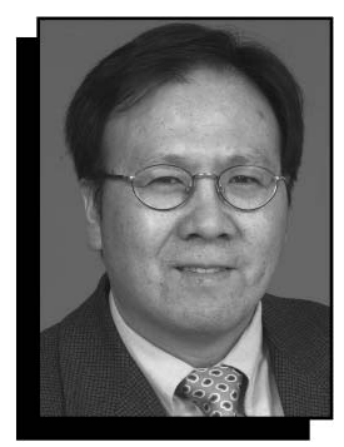

Y.S. Lin

Investigator Award. Koros also received the AIChE Institute Award for Excellence in Industrial Gases Technology in 1995 and the AIChE Separation Division's Clarence Gerhold Award in Separations in 1999. He was elected to the National Academy of Engineering in 2000 and named a fellow of the American Institute of Chemical Engineers in 2002 and of the

American Association for the Advancement of Science in 2003. He has served as editor in chief of the Journal of Membrane Science since 1991 and was secretary of the North American Membrane Society from 1991 to 2004. Koros also served on the editorial boards of the Journal of Macromolecular Science, Part C: Reviews in Macromolecular Chemistry and Physics, Polymer

Contents, and Chemical Engineering Education. Koros has published more than 250 articles and holds 10 U.S. patents in the areas of sorption and transport of small molecules in membranes and barrier materials.

Koros can be reached at the Georgia Institute of Technology, Department of Chemical and Biomolecular Engineering, 311 Ferst Dr. NW, Atlanta, GA 30332 USA; tel. 404-385-2684 and

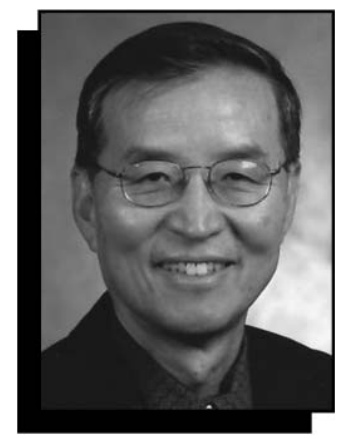

Yi Hua Ma

e-mail wjk@chbe. gatech.edu.

Y.S. Lin is a professor of chemical engineering at Arizona State University. He joined ASU in 2005 after working at the University of Cincinnati.

Lin's research covers inorganic membranes, adsorption, and catalysis. The inorganic membranes studied by his research group range from mesoporous and microporous to dense ceramic and metallic membranes. He has published more than 150 refereed journal papers and holds four patents. He is currently leading a multiuniversity team developing zeolite membranes for hydrogen separation, funded by the U.S. Department of Energy.

Lin can be reached at Arizona State University, Department of Chemical and Materials Engineering, PO Box 876006, Tempe, AZ 85287-6006 USA; tel. 480-965-7769, fax 480965-0037, and e-mail jerry.lin@asu.edu.

Yi Hua Ma is the Francis Manning Professor of Chemical Engineering and director of the Center for Inorganic Membrane Studies at Worcester Polytechnic Institute. He received a

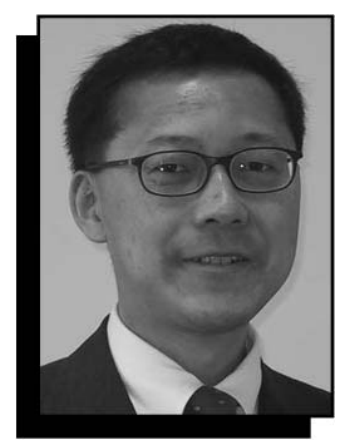

Kazukiyo Nagai

BS degree from National Taiwan University, an MS degree from the University of Notre Dame, and his ScD degree from the Massachusetts Institute of Technology, all in chemical engineering.

Ma's research involves inorganic membranes, Pd and Pd-alloy membranes, and inorganic materials and their adsorptive and transport properties in gases and liquids. He is a fellow of AIChE and was the recipient of the 1994 WPI Board of Trustees' Award for Outstanding Research and Creative Scholarship. Currently, he is collaborating with Shell E \& P International Inc. on a major project on hydrogen production using his patented palladium membrane technology.

Ma can be reached at Worcester Polytechnic Institute, Department of Chemical Engineering, 100 Institute Rd., Worcester, MA 016092280 USA; tel. 508-8315398, fax 508-831-5853, and e-mail yhma@ wpi.edu.

Kazukiyo Nagai is chair of the Center for Polymer Science and an associate professor in the Department of Applied Chemistry at Meiji University in Japan. Nagai received his $\mathrm{BE}$ degree

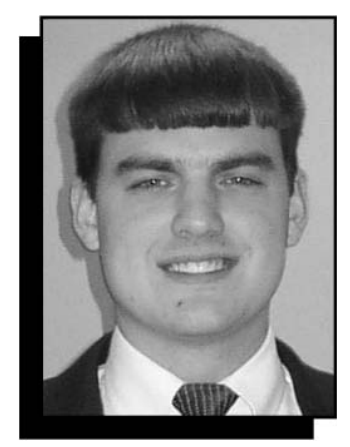

John D. Perry

in 1988, his ME degree in 1990, and his DE degree in 1996 in the Department of Industrial Chemistry at Meiji University. He is a project leader in the Cooperative Research Center for Greenhouse Gas Technologies in Australia, an honorary fellow at the University of Melbourne in Australia, and a research adviser for the Japan Railway Technical Research Institute.

Nagai joined the faculty of Meiji University in 2002

Nagai has more than 10 years of research experience in polymer and membrane science and technologies - particularly gas and vapor separation-at Shin-Etsu Chemical Co. Ltd. in Japan (1990-1993 and 1996-1997), North Carolina State University (1997-2000), and CSIRO Petroleum and CSIRO Molecular Science in Australia (2000-2002). He was named Young Scientist 2003 by the Membrane Society of Japan. Nagai has organized several symposia and workshops as a chair or co-chair in Japan and elsewhere. He has contributed to the membrane community as an editorial committee member of the journal Membrane since 2005. He is also a representative of the Chemical Society of Japan and 


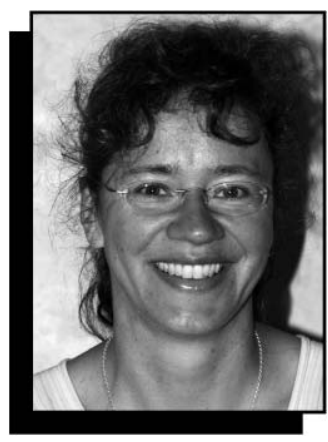

Tanja Pietraß

the Society of Polymer

Science, Japan.

He has authored more than 50 refereed articles and book chapters and holds more than 25 patents on polymers, membranes, and related applications.

Nagai can be reached at the Department of Applied Chemistry, Meiji University, 1-1-1 Higashi-mita, Tama-ku, Kawasaki 214-8571, Japan; tel. 81-44-9347211, fax 81-44-934-7906, and e-mail nagai@ isc.meiji.ac.jp.

John D. Perry is a doctoral student at the Georgia Institute of Technology in Atlanta. After receiving his BS degree in chemical engineering from Clemson University, he was awarded a National Science Foundation Graduate Research Fellowship.

Perry is currently a member of the Koros research group in the School of Chemical and Biomolecular Engineering at Georgia Tech, where his research focuses on the formation of carbon-molecularsieve/polymer hybrids and gas separation membranes.

Perry can be reached at the Georgia Institute of Technology, Department of Chemical and Biomolecular Engineer-

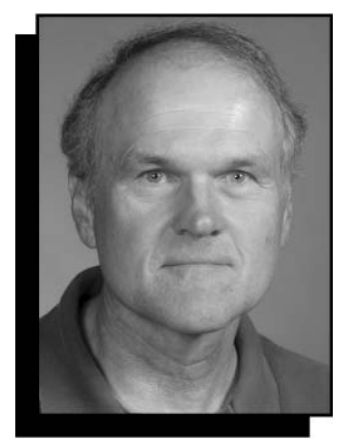

Robert Quinn

ing, 778 Atlantic Dr. NW, Atlanta, GA 30332 USA; tel. 404-385-4717, fax 404-385-2683, and e-mail John.Perry@ chbe.gatech.edu.

Tanja Pietraß is a professor at the New Mexico Institute of Mining and Technology, where she joined the chemistry faculty in 1995. She received tenure and promotion to associate professor in 1999 and became a full professor in 2004. She chaired the department from 2001 to 2006.

Pietraß received a diploma degree in chemistry at the Technical University of Munich, Germany, in 1989. Her work included the synthesis and solid-state nuclear magnetic resonance characterization of the quadrupolar interaction in tetraalkyl-substituted ammonium periodates and perrhenates. She continued her dissertation in the same group, shifting her focus to inorganic and organometallic lithium compounds. In 1992, she joined the Pines group at the University of California, Berkeley, where she worked on optically enhanced Xe NMR spectroscopy in the characterization of surfaces.

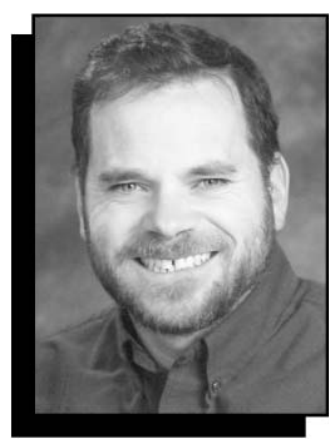

David S. Sholl

She continued her postdoctoral training at the Université Louis Pasteur in Strasbourg, France, in the team of F. Taulelle, investigating ion dynamics in lithiumintercalated tin sulfides using solid-state NMR techniques.

Her present research centers on gas-surface interactions studied by NMR and electron spin resonance. The applications range from heterogeneous catalysis to gas adsorption on carbon nanotubes. She supervises six $\mathrm{PhD}$ degree students.

Pietraß can be reached at the New Mexico Institute of Mining and Technology, Department of Chemistry, 801 Leroy Pl., Socorro, NM 87801 USA; tel. 505835-5586, fax 505-835-

5364, and e-mail tanja@nmt.edu.

Robert Quinn is a research chemist in the Adsorption Technology Center at Air Products and Chemicals Inc. He received his BA and MS degrees in chemistry from Rutgers University in 1969 and 1971, respectively. After several years teaching high school and college chemistry, he earned a $\mathrm{PhD}$ degree in inorganic chemistry from Rutgers

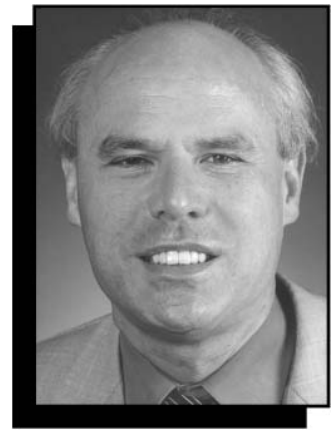

Henk Verweij

University in 1983.

Quinn joined Air

Products in 1985 after

a postdoctoral fellowship at the University of Michigan. He has been involved in a wide range of programs, including membrane and adsorbent-based separations of carbon dioxide and hydrogen sulfide from gas mixtures, new hydrogen synthesis methods, synthesis of oxygenates for diesel fuel blends, and methanol synthesis catalyst poisoning.

His current responsibilities involve research and development of new gas adsorbents, particularly those for carbon dioxide separations.

Quinn can be reached at Air Products and Chemicals Inc., 7201 Hamilton Blvd., Allentown, PA 18195-1501 USA; tel. 610-481-4306, fax 610-481-4566, and e-mail quinnr@ airproducts.com.

David S. Sholl is a professor of chemical engineering at Carnegie Mellon University. He completed his undergraduate training at the Australian National University and earned his $\mathrm{PhD}$ degree from the University of Colorado.
Sholl's research uses atomic-scale computational modeling to study applications of materials in areas such as gas purification and storage, heterogeneous catalysis, and the properties of chiral materials for enantiospecific chemistry.

Sholl can be reached at Carnegie Mellon University, Department of Chemical Engineering, 5000 Fifth Ave., Pittsburgh, PA 15213; tel. 412-268-4207, fax 412268-7139, and e-mail sholl@andrew.cmu.edu.

Henk Verweij is the Orton Chair in Ceramic Engineering at the Ohio State University, Columbus, where he has been since 2001. He received BS and MS degrees in chemical engineering from Delft Technical University in the Netherlands in 1975, and a PhD degree from Eindhoven Technical University in 1980.

Verweij joined Philips Research Labs in Eindhoven in 1975 as a research scientist. In 1992, he became a professor of inorganic materials science at the University of Twente.

His research areas include physical chemistry, solid-state thermodynamics and transport, and ceramic processing.

Verweij can be reached at Ohio State University, Department of Materials Science and Engineering, 2041 North College Rd., 291A Watts Hall, Columbus, $\mathrm{OH}$ 43210-1178 USA; tel. 614-247-6987 or 614-292-7417, fax 614688-4949, and e-mail verweij@matsceng. ohio-state.edu. 